\title{
A Multiobjective Optimal Operation of a Stand-Alone Microgrid Using SAPSO Algorithm
}

\author{
Guoping Zhang $\perp^{1},{ }^{1}$ Weijun Wang $\triangle{ }^{1}$ Jie Du $\perp^{2},{ }^{2}$ and Hua Liu ${ }^{1}$ \\ ${ }^{1}$ Department of Military Installations, Army Logistics University of PLA, Chongqing 401331, China \\ ${ }^{2}$ Electric Power Research Institute, Chongqing Electric Power Company, Chongqing 401123, China \\ Correspondence should be addressed to Weijun Wang; wjwang636@126.com
}

Received 19 September 2019; Revised 25 November 2019; Accepted 4 January 2020; Published 7 March 2020

Academic Editor: Pietro Varilone

Copyright (c) 2020 Guoping Zhang et al. This is an open access article distributed under the Creative Commons Attribution License, which permits unrestricted use, distribution, and reproduction in any medium, provided the original work is properly cited.

\begin{abstract}
Microgrid is an effective way to utilize renewable energy resources, especially for satisfying the electricity requirements in remote islands. The operation optimization of an island microgrid is critical to ensure the effective performance of the whole microgrid system, and it is usually a multiconstrained and multiobjective optimization problem. The main contribution of this study is an operation optimization method for the stand-alone microgrid system in a remote island, which includes wind, PV, battery, and diesel generator. In this paper, a novel operation optimization model for stand-alone microgrid is proposed, in which the battery system is considered separately; the multiobjective day-ahead optimization model considering economic cost, battery depreciation cost, and environmental protection cost is established. In the optimization, the output power of diesel generator and energy storage system are chosen as the decision variables. For this purpose, an efficient search algorithm combining the particle swarm optimization (PSO) algorithm and the simulated annealing (SA) algorithm is developed. The hybrid algorithm is applied to search for the Pareto solution set of the optimization problem. The search results are compared with those from traditional PSO algorithm. Also, a grey target decision-making theory based on the entropy weight method is proposed to identify the best tradeoff scheduling scheme among all the solutions, and the results are compared with those from two other commonly used subjective and objective methods. The results show that the proposed optimization method can be applied to the day-ahead operation optimization of the microgrid system and help the user obtain the best compromise operation scheme for stand-alone microgrid.
\end{abstract}

\section{Introduction}

Nowadays, there are still many islands that have no access to the public power grid; these areas are highly dependent on traditional diesel generators to supply their energy needs $[1,2]$. The islands are usually rich in renewable energy resources, such as solar and wind resources [3]. Normally, the variation of renewable resources and the time distribution of load demand may not match exactly [4]. The main challenge in developing renewable resources is their stochastic and intermittent natures. In order to eliminate the impact of this problem, the microgrid that integrates a variety of renewable energy resources has been proposed [5]. For remote areas, previous investigations have shown that this approach can significantly improve the reliability of the whole power system $[6,7]$.

In the past years, many studies have focused on the optimal design and sizing of microgrid system to minimize the life cycle cost while satisfying the power quality [8-11]. Some powerful optimal design software tools such as HOMER [12] and HYBRID2 [13] are developed. With the increasing penetration rate of renewable energy generation, the uncertainty caused by the randomness and intermittency of renewable energy resources has imposed a considerable impact on the safe and reliable operation of the microgrid [14].

At present, study of the optimal operation of microgrid mainly considers its operation cost [15], environmental cost [16], power supply reliability [17], and so on. Guo et al. [18] proposed a multiobjective optimization model for isolated microgrid system, which aimed at the confliction of interests between the distribution company and the distributed generation owners. Azaza and Wallin [19] made a trade-off between three conflicting objectives, namely, the reliability of the system, the cost of electricity production, and the operation environmental impact. Zhang et al. [20] used 
forecast load information instead of past information for optimally designing a hybrid renewable energy scheme (WT/PV/BAT) to minimize TLCC of the scheme.

However, the microgrid optimal scheduling model is a multiconstrained, multiobjective problem. Different methods are used to solve this problem. The most common approach is to transform the multiobjective optimization problem into one single-objective optimization problem by using the linear weighted sum method [21]. In the previous study, some other classic approaches are adopted, such as iterative technique [22], mixed-integer linear programming [23], design space concept [24], and min-max approach [25]. Considering that some objectives are mutually exclusive, the metaheuristic optimization techniques are found to be more acceptable than traditional classic methods for the optimization of microgrid system because of their ability to search global optimum, fast convergence, and good calculation accuracy [26], which can be divided into two groups: one is the evolutionary algorithms (EAs), which is based on emulating the process of natural evolution and survival of the fittest, such as genetic algorithm (GA) [27] and evolutionary programming (EP) [28], and the other is the swarm intelligence algorithms (SIAs), whose operation is based on social and cooperative behaviors of individuals, such as particle swarm optimization (PSO) [29], bee algorithm [26], and ant colony algorithm [30].

Cagnano et al. [31] proposed a new strategy that manages the active power reserve in isolated microgrid for maximization of the grid's reservation. This work is done by adopting direct Lyapunov theorem and sensitivity analysis, but the cost function is not considered. Wu et al. [32] presented the dynamic economic dispatch model of a combined heat and power (CHP) microgrid system. In order to minimize the total cost, namely, operating cost and pollutant treatment cost, the biobjective problem is simplified by summing these two costs directly. An improved particle swarm optimization (PSO) algorithm is proposed to solve the objective function. But the relationship between the two costs is not discussed. Karimi et al. [33] presented a multiobjective operational model for a grid-connected microgrid considering the cost, security, and reliability of the system simultaneously. To solve the proposed model, a set of Pareto solutions is obtained first by using the weighted sum approach. The hybrid multiobjective and multiattribute decision-making framework is applied to achieve the best operation status. Moradi et al. [34] developed a multiobjective optimization model including fuel consumption cost, total voltage variation, and the voltage stability index. A hybrid optimization algorithm combining the harmony algorithm (HS) and the genetic algorithm (GA) is proposed to solve the problem. The fuzzy method is employed to find the optimum solution among all the nondominated results. Zhang et al. [35] to minimize the total life cycle cost and increase the accuracy of size optimization of the independent hybrid renewable energy systems proposed a new hybrid optimization algorithm based on three algorithms: chaotic search, harmony search, and simulated annealing. The forecasting weather data is used along with artificial neural networks to improve the accuracy of the size optimization algorithm results.

Although various studies on microgrid operation optimization from different aspects and different techniques have been reported, almost all of them have included the battery depreciation cost into the cost of power generation without considering it separately. The energy storage battery system is critical to stand-alone microgrid on an island. Because of the harsh environment of island and the frequent charging and discharging of battery bank, the lifespan of battery bank will be greatly affected, which will accelerate the depreciation of battery bank. During the operation optimization process, it is necessary to consider the battery system separately. Also, both the optimization techniques and the optimal decision-making methods need further research.

In this paper, a mathematical model for each device of the microgrid system is introduced at first. In order to use the battery more reasonably, a novel battery operation cost model is proposed and chosen as one of the optimization objectives. To realize the economic operation of stand-alone microgrid, a multiobjective function is defined based on minimize the fuel cost, operation and maintenance cost, environmental cost, and battery depreciation cost subject to constraint conditions. An efficient method is needed to solve this multiobjective function. Due to the features of particle swarm optimization algorithm and simulated annealing algorithm, an improved hybrid SAPSO algorithm is developed to obtain Pareto front solutions for the multiobjective optimization problem. The results are compared with those obtained by traditional particle swarm optimization algorithm. In order to help user choose the optimal scheme, the grey target decision-making strategy based on entropy weight method is proposed to identify the best compromise solution from the obtained Pareto solution set. At last, a stand-alone microgrid containing wind, PV, battery, and diesel generator in Yongxing Island, China, is chosen as one case study to verify the effectiveness of the proposed methods.

This paper is organized as follows. The introduction is given in Section 1. In Section 2, description of the proposed microgrid system and modelling of major components are presented. The optimization problem is analysed in Section 3. Section 4 explains the proposed methodology. The results are discussed in Section 5. The conclusion is shown in Section 6.

\section{Model of Major Components}

The stand-alone microgrid system is composed of photovoltaic arrays, wind power generation, diesel generators, energy storage battery system, power conversion system (PCS), loads, and energy management system (EMS), as shown in Figure 1.

The AC bus mode is used in this microgrid system, and all micro sources are directly integrated into the common AC bus. The photovoltaic array contains multiple PV modules, each of which is directly incorporated into the common AC bus through a string inverter. The wind 


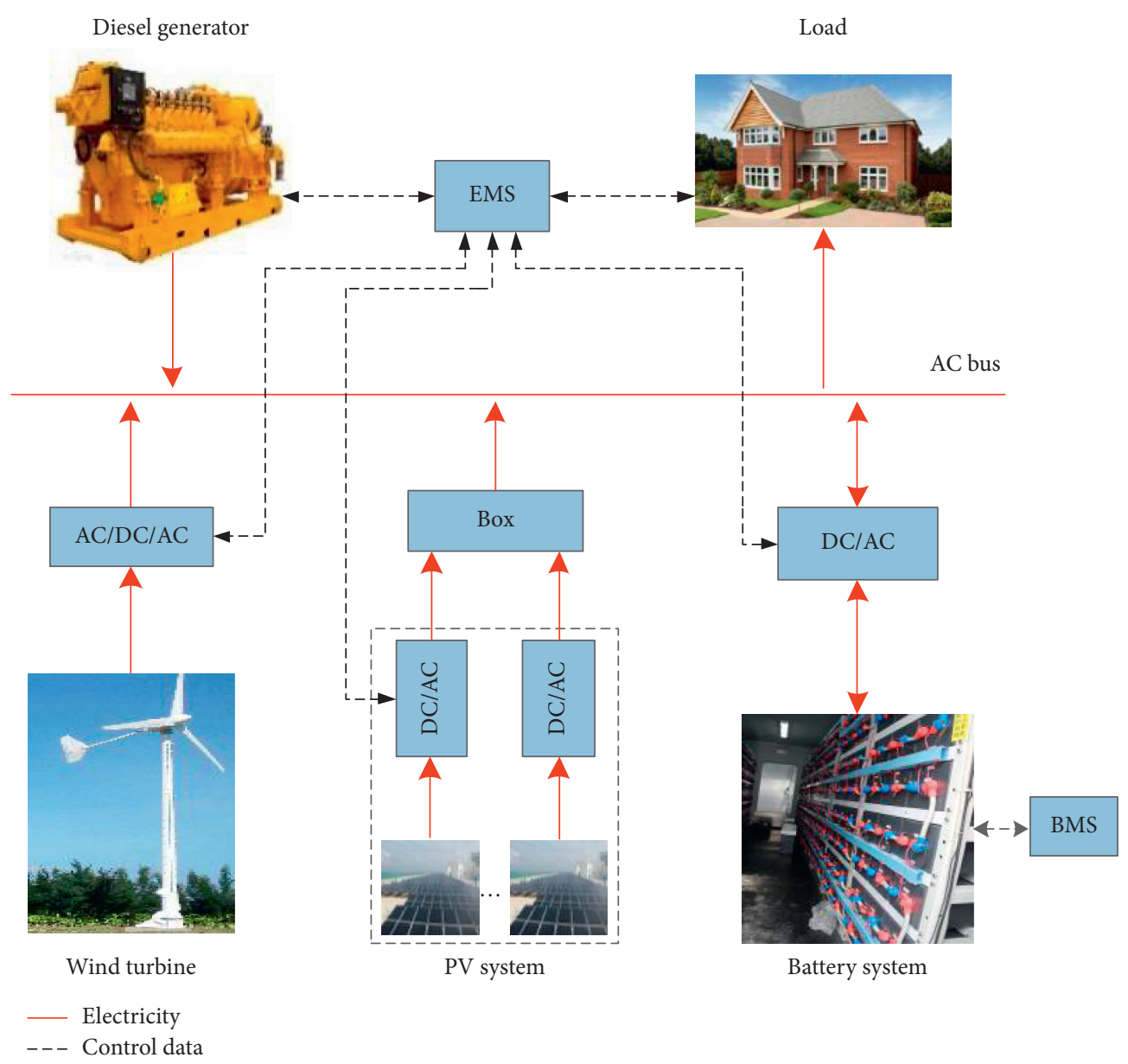

Figure 1: The schematic configuration of a PV-wind-battery-diesel stand-alone microgrid system.

generation consists of several permanent magnet directdrive wind turbines that are connected to the $\mathrm{AC}$ bus by $\mathrm{AC} / \mathrm{DC} / \mathrm{AC}$ converters. The maximum power point tracking (MPPT) control strategy is adopted for PV and wind generation, which aims to maximize the utilization of solar and wind energy. The energy storage battery system is integrated into the AC bus via a bidirectional power conversion system (PCS) and plays the role of peak clipping and valley filling in the system. Under normal circumstances, the diesel generators provide frequency and voltage support for the system as the main power source, while the energy storage PCS adopts the constant power control strategy. When the diesel generator fails or the load is low, the diesel generator will be turned off, and the energy storage PCS becomes the main power source working in $\mathrm{V} / \mathrm{F}$ control mode. The whole microgrid system achieves stable and economic operation under the coordinated control of the energy management system (EMS).
2.1. PV System. The PV system works by converting solar energy into electrical energy. Therefore, the output power is related not only to the solar irradiation but also to the performance of the photovoltaic module itself. The ambient temperature also affects the output power of the component. The temperature coefficient should be taken into consideration. Thus the output of a PV system can be calculated by the following equation [36]:

$$
P_{\mathrm{PV}}(t)=P_{\text {rate_PV }} \eta_{\mathrm{PV}} G(t)\left[1+\alpha_{\mathrm{TP}}\left(T_{\mathrm{PV}}(t)-T_{\mathrm{STC}}\right)\right],
$$

where $P_{\mathrm{PV}}(t)$ is the real output power of $\mathrm{PV}$ system, $P_{\text {rate_PV }}$ is the nominal capacity of PV array, $\eta_{\mathrm{PV}}$ is the deteriorating factor, $G(t)$ is the actual solar irradiation on the PV panel, $\alpha_{\mathrm{TP}}$ is the temperature factor $\left(\% /{ }^{\circ} \mathrm{C}\right), T_{\mathrm{STC}}$ is the ambient temperature of $\mathrm{PV}$ cell under standard test condition, normally $25^{\circ} \mathrm{C}$, and $T_{\mathrm{PV}}(t)$ is the temperature on the surface of PV panel; it is usually different from the ambient temperature, which can be obtained from equation (2) as follows [37]:

$$
T_{\mathrm{PV}}(t)=\frac{T(t)+\left(T_{\mathrm{NOCT}}-20\right)((G(t)) /(0.8))\left(1-\eta_{\mathrm{STC}}\left(\left(1-25 \alpha_{\mathrm{TP}}\right)\right) /(0.9)\right)}{1+\left(T_{\mathrm{NOCT}}-20\right)((G(t)) /(0.8))\left(\left(\alpha_{\mathrm{TP}} \eta_{\mathrm{STC}}\right) /(0.9)\right)},
$$


where $\eta_{\text {STC }}$ is the efficiency at standard test condition, \%, $T_{\text {NOCT }}$ is the nominal operating temperature of PV cell, and $T(t)$ is the ambient temperature, ${ }^{\circ} \mathrm{C}$.

2.2. Wind Turbine. Wind turbines convert the kinetic energy of wind into rotational kinetic energy of the blades and ultimately into electrical energy [38]. A type of permanent magnet direct-drive wind turbine manufactured by GHREPower is adopted in this microgrid. The output power of wind turbine can be calculated by the following equation [39]:

$$
P_{\mathrm{WT}}(t)= \begin{cases}0, & v<v_{\text {cut_in }}, v>v_{\text {cut_out }}, \\ P_{\text {rated_WT }} \times\left(\frac{v^{2}-v_{\text {cut_in }}^{2}}{v_{R}^{2}-v_{\text {cut_in }}^{2}}\right), & v_{\text {cut_in }} \leq v \leq v_{r}, \\ P_{\text {rated_WT }}, & v_{r} \leq v \leq v_{\text {cut_out }},\end{cases}
$$

where $v$ is the wind speed, $v_{r}$ is the rated wind speed of wind turbine, $13 \mathrm{~m} / \mathrm{s}, P_{\text {rated_WT }}$ is the rated output power of WT, and $v_{\text {cut in }}$ and $v_{\text {cut_out }}$ refer to the cut-in and cut-out wind speed of WT, $3 \mathrm{~m} / \mathrm{s}$ and $25 \mathrm{~m} / \mathrm{s}$, respectively.

2.3. Diesel Generator. Because of the randomness and volatility of renewable resources, there may be a mismatch between power generation and load demand in the renewable energy generation system. Especially for a standalone microgrid, it is quite necessary to deploy one or more diesel generators [40]. The fuel consumption rate of diesel generator is one of the most important parameters in microgrid operation, since both the operating and maintenance cost and the pollutant emission are directly dependent on fuel consumption. The hourly fuel consumption rate of diesel generator can be formulated as follows [41]:

$$
F(t)=F_{0} P_{\text {rate_gen }}+F_{1} P_{\text {gen }}(t),
$$

where $F(t)$ is the hourly fuel consumption of diesel generator, L/h, $P_{\text {rate_gen }}$ denotes the nominal power and $P_{\text {gen }}(t)$ is the real output power at time $t$, and $F_{0}$ and $F_{1}$ are the intercept coefficient and slope of the fuel consumption curve, L/kW, describing the relationship between the fuel consumption and electrical power and are approximated to 0.084 and 0.24 , respectively [42].

2.4. Battery System. The energy storage battery system is able to balance the power of stand-alone microgrid system by storing the excess energy or supplying the power deficit. It is usually composed of one or more individual batteries. The state of charge (SOC) of battery system at time $t$ is determined by the total available generation and the load demand, as well as the SOC at time $t-1$, which can be calculated as follows [43].
For battery charging,

$$
\begin{aligned}
\operatorname{SOC}(t)= & (1-\delta) \cdot \operatorname{SOC}(t-1)+\left(P_{\text {gen }}(t)-P_{\text {load }}(t)\right) \\
& \cdot \eta_{b s, c h} \cdot \frac{\Delta t}{E_{\text {bat }}} .
\end{aligned}
$$

For battery discharging,

$$
\begin{aligned}
\operatorname{SOC}(t)= & (1-\delta) \cdot \operatorname{SOC}(t-1)-\left(P_{\text {load }}(t)-P_{\text {gen }}(t)\right) \\
& \cdot \frac{\Delta t}{\eta_{b s, \text { dis }} E_{\text {bat }}},
\end{aligned}
$$

where $\delta$ is the self-discharging factor, $\operatorname{SOC}(t)$ is the state of charge of battery, $P_{\text {gen }}(t)$ is the total available energy generated by micro sources, $P_{\text {load }}(t)$ is the load demand in time interval, $E_{\mathrm{bat}}$ is the capacity of the battery bank, $\Delta t$ is the time interval, and $\eta_{b s, c h}$ and $\eta_{b s \text {,dis }}$ are the battery charging and discharging efficiency including the inverter, respectively. The lead-acid battery GFM-800RC, manufactured by NARADA, is adopted in the microgrid system.

\section{Multiobjective Optimization Model}

In order to minimize the economic cost, the battery depreciation cost, and the environmental cost of microgrid system, a multiobjective optimization model is established in this paper. The objective function is as follows:

$$
\begin{aligned}
\min F(x) & =\min \left(\left[f_{c}(x), f_{b}(x), f_{e}(x)\right]^{T}\right), \\
f_{c}(x) & =\sum_{t=1}^{T}\left[C_{F}+C_{\mathrm{OM}}\right], \\
f_{b}(x) & =\sum_{t=1}^{T} C_{B}, \\
f_{e}(x) & =\sum_{t=1}^{T} C_{E},
\end{aligned}
$$

where $f_{c}(x)$ is the economic cost, $f_{b}(x)$ is the battery depreciation cost, $f_{e}(x)$ is the environmental cost, $C_{F}$ is the fuel cost of diesel generator, $C_{\mathrm{OM}}$ is the equipment operation and maintenance cost, $C_{B}$ is the battery depreciation cost, $C_{E}$ is the environmental cost of pollutant emissions affecting the environment, and $T$ is the number of time intervals in the optimization period, which is 24 hours in this paper.

Due to the stochastic and intermittent natures of solar irradiance and wind speed, the output power of PV system and wind turbines are uncontrollable. Therefore, the output power of diesel generator and battery system are chosen as the optimization decision variables in this paper. The optimization period contains 24 time intervals in one day, so the decision variables are 24-dimensional power vectors.

3.1. Economic Cost. Since PV and wind generations use renewable energy, the cost of both is not considered. The fuel consumption cost of diesel generator can be expressed as 


$$
C_{F}=\sum_{i=1}^{n} f\left(P_{i}(t)\right) C_{\text {fuel }},
$$

where $f\left(P_{i}(t)\right)$ represents the amount of diesel consumed by the diesel generator in time interval, $\mathrm{L}$, and $C_{\text {fuel }}$ is the unit price of diesel, $\$ / \mathrm{L}$.

The operation and maintenance cost of the microgrid is linearly related to the electrical energy produced by the system. The expression of $C_{\mathrm{OM}}$ is

$$
C_{\mathrm{OM}}=\sum_{i=1}^{n} P_{i}(t) K_{\mathrm{OM}, i},
$$

where $P_{i}(t)$ is the output power of unit $i$ at time $t, K_{\mathrm{OM}, i}$ is the operation and maintenance cost per kilowatt of unit $i$, $\$ / \mathrm{kWh}$, and $n$ is the number of generation units.

3.2. Battery Depreciation Cost. Due to the fact that the harsh natural environment of the island will accelerate aging of battery, the depreciation cost of battery system is adopted as one of the optimization objectives. Meanwhile, frequent charging and discharging will reduce the lifespan of the leadacid battery bank, thereby indirectly increasing the operating cost of the system. Converting the replacement cost of the lead-acid battery into the operating cost can more accurately reflect the impact of the battery life on the operating cost. To this end, this paper designs a battery depreciation cost objective function that takes into account the replacement cost of lead-acid battery:

$$
\begin{aligned}
C_{B}= & \sum_{t=1}^{T}\left[C_{\text {bat,DP }}(t)+C_{\text {bat }, \mathrm{OM}}(t)\right]=\sum_{t=1}^{T} \frac{C_{\text {bat,rep }}}{2 E_{\text {lifetime }}}\left|P_{\text {bat }}(t)\right| \\
& +\sum_{t=1}^{T} K_{\text {bat }, \mathrm{OM}}\left|P_{\text {bat }}(t)\right|,
\end{aligned}
$$

where $C_{\text {bat,DP }}(t)$ is the battery depreciation cost, $C_{\text {bat,OM }}(t)$ is the operation and maintenance cost of battery, $C_{\text {bat,rep }}$ is battery replacement cost, $E_{\text {lifetime }}$ is the total charging and discharging energy of battery lifetime, $\mathrm{kWh}, P_{\text {bat }}(t)$ is the charging and discharging power of the battery at time $t$, positive at the time of discharging and negative at the time of charging, and $K_{\text {bat,OM }}$ is the unit operation and maintenance cost coefficient of the battery, $\$ / \mathrm{kW}$.

Generally, the total amount of recyclable charging and discharging energy in the battery lifespan is basically a constant [43]. The relationship of the total number of cycles to failure and the depth of discharge can be described by a double exponential function [44]. The relationship curve of both is depicted in Figure 2:

$$
N_{\mathrm{DOD}}=a_{1}+a_{2} \cdot e^{-a_{3} \cdot \mathrm{DOD}}+a_{4} \cdot e^{-a_{5} \cdot \mathrm{DOD}},
$$

where $N_{\text {DOD }}$ is the number of cycles to failure, DOD is the depth of discharge of battery, and parameters $a_{1}$ to $a_{5}$ are obtained via a regression on empirical lifetime test data provided by the battery manufacturer, which are 1505.89, 9687.24, 4.90, 9845.09, and 6.59, respectively [44].

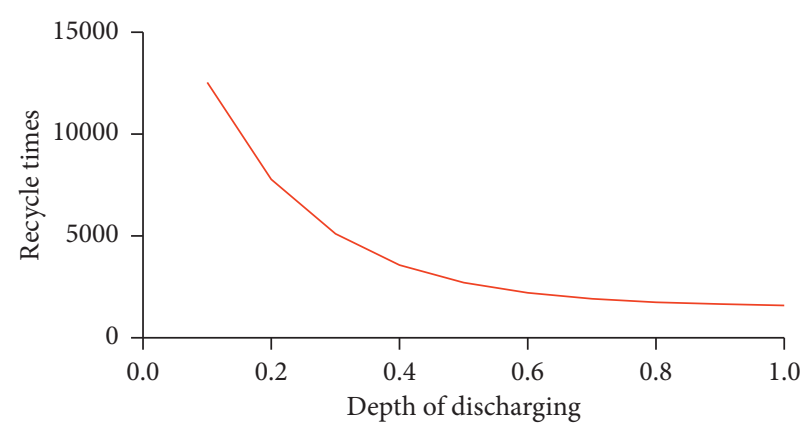

FIgure 2: The relationship between $N_{\text {DOD }}$ and DOD.

Therefore, at a given DOD, the total charging and discharging energy during battery's lifetime is [42]

$$
E_{\text {lifetime }}=2 E_{\text {rated }} \cdot \mathrm{DOD} \cdot N_{\mathrm{DOD}} \text {. }
$$

3.3. Environmental Cost. Diesel generators release polluting gases such as $\mathrm{SO}_{2}, \mathrm{CO}_{2}, \mathrm{CO}$, and $\mathrm{NOx}$. The emission of these gases will pollute the environment, and the environmental protection department will levy a corresponding environmental damage penalty for environmental treatment. The environmental cost $C_{E}$, namely, the penalty fees of pollutant emission consisting of $\mathrm{NO}_{\mathrm{X}}, \mathrm{CO}_{2}, \mathrm{CO}$, and $\mathrm{SO}_{2}$, can be calculated as follows [45]:

$$
C_{E}=\sum_{i=1}^{n} \sum_{j=1}^{m}\left(V_{e_{j}} Q_{i j}+V_{j}\right),
$$

where $V_{e_{j}}$ is the environmental value standard of pollutant emission, $Q_{i j}$ is the amount of pollutant emission, $V_{j}$ is the penalty factor of the $j$ th gas emission by the $i$ th micro power source, $n$ is the number of micro power sources in the microgrid system, and $m$ is the total number of the polluting gases.

3.4. Constraint Conditions. Considering the system power balance and the physical limits of the power generation units, the above operation optimization model must be subject to the following constraints.

Power generation and consumption should always be kept in balance:

$$
P_{\text {load }}(t)=P_{\mathrm{pv}}(t)+P_{\mathrm{wt}}(t)+P_{\mathrm{bat}}(t)+P_{\mathrm{de}}(t)
$$

where $P_{\text {load }}(t)$ is the load demand, $P_{\text {bat }}(t)$ is the output power of the battery, and positive means discharging and negative means charging; $P_{\mathrm{de}}(t)$ is the output of the diesel generator, and $P_{\mathrm{pv}}(t)$ and $P_{\mathrm{wt}}(t)$ are the output of $\mathrm{PV}$ system and wind turbine, respectively.

The output constraints of PV system and wind turbine are

$$
\begin{aligned}
& 0 \leq P_{\mathrm{pv}}(t) \leq P_{\mathrm{pv}, \max }, \\
& 0 \leq P_{\mathrm{wt}}(t) \leq P_{\mathrm{wt}, \max },
\end{aligned}
$$

where $P_{\mathrm{pv}, \max }$ and $P_{\mathrm{wt} \text { max }}$ are the maximum output power of PV system and wind turbine, respectively. 
The constraints of battery system are

$$
\begin{aligned}
\mathrm{SOC}_{\text {min }} & \leq \mathrm{SOC}(t) \leq \mathrm{SOC}_{\text {max }}, \\
-P_{\text {bat,max }} & \leq P_{\text {bat }}(t) \leq P_{\text {bat,max }},
\end{aligned}
$$

where $P_{\text {bat,max }}$ is the maximum power of charging and discharging the battery; $\mathrm{SOC}_{\min }$ and $\mathrm{SOC}_{\max }$ are the lower and upper limits of the SOC, respectively.

Moreover, the initial SOC and the SOC at the end must be equal:

$$
\mathrm{SOC}_{\text {initial }}=\mathrm{SOC}_{\text {end }} \text {. }
$$

The operating constraint of diesel generator is

$$
k_{\mathrm{de}, \min } P_{\mathrm{de}, \max } \leq P_{\mathrm{de}}(t) \leq k_{\mathrm{de}, \max } P_{\mathrm{de}, \max },
$$

where $P_{\mathrm{de}, \max }$ is the output upper limit of diesel generator; $k_{\mathrm{de} \text {,min }}$ and $k_{\mathrm{de} \text {,max }}$ denote the minimum and maximum load rates of the diesel generator, respectively. Considering the economical operation and spinning reserve of system, the values of $k_{\mathrm{de} \text {,min }}$ and $k_{\mathrm{de} \text {,max }}$ are set to 0.3 and 0.8 based on manufacturers' suggestion.

The block diagram of operating strategy is shown in Figure 3. Considering the system's operation efficiency and power supply reliability and the fact that diesel generator and storage battery system are controllable sources, in order to utilize renewable energy sources as much as possible, the economic operation strategy of diesel generator is applied, and the charging/discharging power of battery is dispatched at first.

When the net power is less than or equal to the lower limit of diesel generator's economic operating ranges, it will run at the lower limit or be shut down, and the energy storage battery will balance system power. When the net power is between the upper and lower limits of diesel generator's economic operating ranges, the state of charge of battery is kept at an appropriate level, and the battery system is charged or discharged to make sure diesel generator runs within the economic operating ranges. When the net power is greater than the upper limit of diesel generator's economic operating ranges, and if the battery system has the ability to regulate, it will share the excess load; otherwise the unimportant load will be cut off.

\section{Methodology}

4.1. Improved SAPSO Algorithm. The particle swarm optimization algorithm is derived from the simulation of foraging behavior of flocks and fish populations. Particles determine the next move through their own experience and the best experience of their peers. Each particle in the swarm is a potential solution to the problem and corresponds to a fitness value determined by its position. The velocity of the particle determines the direction and distance of its motion, and the velocity is dynamically adjusted with the movement experience of itself and other particles, thus achieving the individual's optimization in the solvable space. The speed and position update formula are expressed in following equations:

$$
\begin{aligned}
v_{i, j}(k+1)= & v_{i, j}(k)+c_{1} r_{1}\left(p_{i, j}(k)-x_{i, j}(k)\right) \\
& +c_{2} r_{2}\left(p_{g, j}(k)-x_{i, j}(k)\right), \\
x_{i, j}(k+1)= & x_{i, j}(k)+v_{i, j}(k+1), \quad j=1, \ldots, n,
\end{aligned}
$$

where $c_{1}$ and $c_{2}$ are the learning factors, $v_{i, j}$ and $x_{i, j}$ are the velocity and position of particles, $p_{i}$ is the best position found by each particle so far, $p_{g}$ is the global best position found by all particles in the entire population, and $r_{1}$ and $r_{2}$ are random numbers between 0 and 1 .

The basic idea of simulated annealing algorithm is to use a thermodynamic system to present optimization process by gradually cooling the system to the lowest energy state [46]. The energy of the system is regarded as the objective function of the optimization problem. According to the principle of thermodynamics, when the temperature is $T$, the likelihood of temperature drop with the energy difference $\Delta P$ is $P(\Delta E)$, which is expressed as

$$
P(\Delta E)=\exp \left(\frac{\Delta E}{T}\right)
$$

where $E$ is the internal energy of temperature $T ; \Delta E$ is energy difference.

The Metropolis criterion is used to judge whether to accept new solution or not. The iteration process of "generating new solutions, judging, accepting, or abandoning" was realized to find the optimal solution at this temperature:

$$
x(i+1)= \begin{cases}x_{\text {new, }}, & \text { if } \exp \left(\frac{\Delta E}{T}\right)>r, \\ x(i), & \text { o.w., }\end{cases}
$$

where $r$ is a random number in the range $[0,1], x(i)$ is the solution at an iteration, $E(x(i))$ is the corresponding objective function, and $x_{\text {new }}$ is the new solution.

Although the particle swarm optimization (PSO) algorithm has a fairly fast convergence speed, it is easy to fall into a local optimum and produce premature convergence. The simulated annealing (SA) algorithm has a simple calculation process and strong robustness, but the convergence speed is slow. Therefore, the hybrid algorithm combined the particle swarm optimization and the simulated annealing algorithm is proposed to make up for the defects of both algorithms.

In this paper, the SAPSO algorithm adopts PSO with a compression factor $\chi$, which is able to ensure the convergence of PSO algorithm and select the boundary of speed by choosing appropriate parameters limits. Since the optimal population position is used in the speed update formula, all particles will move to the global best position of the entire population. If the best position of the population is at a local optimum, all particles will tend to the local optimum. Therefore, in order to improve the ability of PSO algorithm to avoid falling into local extremum, a roulette theory is used to determine a globally optimal alternative value $\dot{p}_{g}$ from $p_{i}$. Rewrite the speed update formula: 


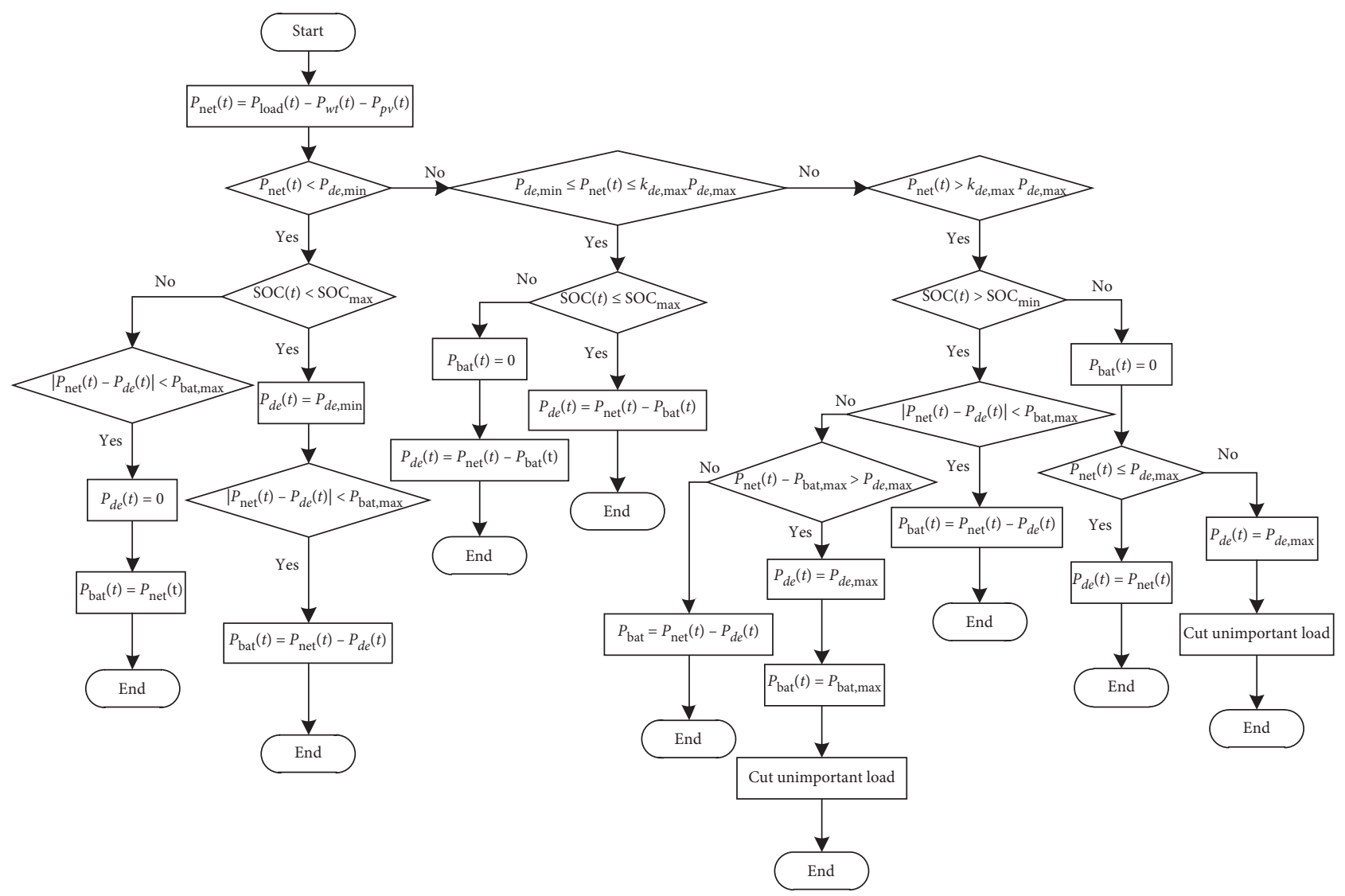

FIGURE 3: The block diagram of operating strategy.

$$
\begin{aligned}
& v_{i, j}(k+1)= \chi\left[v_{i, j}(k)+c_{1} r_{1}\left(p_{i, j}(k)-x_{i, j}(k)\right)\right. \\
&\left.+c_{2} r_{2}\left(\dot{p}_{g, j}(k)-x_{i, j}(k)\right)\right], \\
& x=\frac{2}{\left|2-C-\sqrt{C^{2}-4 C}\right|}, \quad C=c_{1}+c_{2}, C>4 .
\end{aligned}
$$

By borrowing the mechanism of simulated annealing algorithm, $p_{i}$ is a special solution that is worse than $p_{g}$; the jump probability of $p_{i}$ with respect to $p_{g}$ at temperature $t$ can be calculated as follows:

$$
P\left(p_{i}\right)=\frac{e^{-\left(f_{p i}-f_{p g}\right) / t}}{\sum_{i=1}^{N} e^{-\left(f_{p i}-f_{p g}\right) / t}}
$$

where $N$ is the population size, $t$ is the current temperature, and $f$ represents the objective function value.

The calculation flowchart of SAPSO algorithm is shown in Figure 4. The penalty functions are used to handle the equality and inequality constraints. The main steps of SAPSO algorithm are as follows:

Step 1 (initialization): set up the initial parameters, such as the output power of generation units, random control parameters, population size, $N$, maximum number of iterations, $M$, initial and minimum

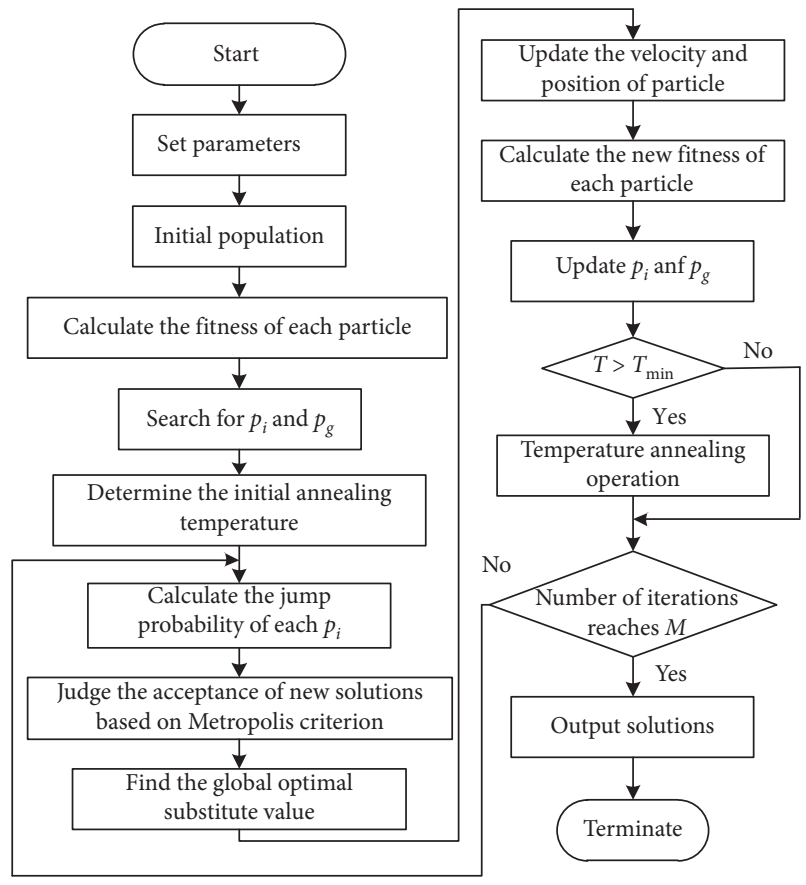

FIGURE 4: Flowchart of SAPSO algorithm.

annealing temperatures, $T_{0}$ and $T_{\min }$, temperature attenuation coefficient, $k$, and learning factors, $c_{1}$ and $c_{2}$, respectively. Initial population is generated randomly. 
Step 2 (fitness calculation): calculate the fitness value of each particle in the initial population. Find the optimal value of the objective function, and record the individual best position $p_{i}$ and global best position $p_{g}$.

Step 3 (probability): determine the initial annealing temperature $T_{0}$, and calculate the fitness of jump probability corresponding to each $p_{i}$ at the current temperature according to equation (25).

Step 4 (selection): according to the Metropolis criterion to judge whether to accept the current solution or not, use the roulette theory to find the global optimal substitute value $\dot{p}_{g}$, and update the global optimal position from all individual extremums.

Step 5 (updating): update the velocity and position of the particles by using equations (19), (23), and (24). Calculate the new fitness of each particle, and update the best position $p_{i}$ of each particle and the global best position $p_{g}$ of the population. Determine whether the annealing temperature is less than the termination temperature $T_{\min }$, and if so, jump to step 7; otherwise, continue execution.

Step 6 (annealing): perform the temperature annealing operation.

Step 7 (end): judge whether the iteration has reached the maximum number; if it is not reached, go to step 3; otherwise, stop iteration, and output results.

4.2. Grey Target Decision-Making Theory. In this paper, a multiobjective grey target decision-making theory based on entropy weight method is used to select a satisfactory solution from the Pareto optimal solution set obtained by SAPSO algorithm. Setting a target center in the grey target region formed by all the feasible solutions, the distance between these solutions and the target center is an important criterion for grey target decision. The grey target decision sorts all the schemes according to the bull's eye distance of each scheme and chooses the shortest one as the optimum. Based on the information entropy theory, the weighting factor of each objective and the bull's eye distance of each scheme are obtained without relying on the experience of experts or the preferences of decisionmakers. The credibility and realism of decision-making are improved.

Step 1: initialization of the sample matrix

Assume that there are $m$ decision-making schemes, and each scheme has $n$ objectives. Based on the Pareto optimal solution set obtained by SAPSO algorithm, the initial sample matrix $\mathbf{X}$ can be established as follows:

$$
\mathbf{X}=\left(x_{i j}\right)_{m \times n}=\left[\begin{array}{ccc}
x_{11} & \cdots & x_{1 n} \\
\vdots & \ddots & \vdots \\
x_{m 1} & \cdots & x_{m n}
\end{array}\right]
$$

Step 2: calculation of the weighting factors

According to target values of each scheme, different specific weights $y_{i j}$ and entropy values $E_{j}$ are calculated, and the weighting factors are obtained by using equation (29).

$$
\begin{aligned}
y_{i j} & =\frac{x_{i j}}{\sum_{i=1}^{m} x_{i j}}, \quad x_{i j} \geq 0, \\
E_{j} & =-\frac{1}{\ln m} \sum_{i=1}^{m} x_{i j} \ln y_{i j}, \quad E_{j}>0, \\
\omega_{j} & =\frac{\left(1-E_{j}\right)}{\sum_{j=1}^{n}\left(1-E_{j}\right)} .
\end{aligned}
$$

Step 3: normalization of the sample matrix.

The decision matrix $\mathbf{V}$ is solved based on the "reward and fine" operator $z_{j}$ and sample matrix $\mathbf{X}$, where the operator $z_{j}$ is

$$
z_{j}=\frac{1}{m} \sum_{i=1}^{m} x_{i j}, \quad j=1,2, \ldots, n .
$$

If the target value is a benefit indicator, the normalization expression is as follows:

$$
v_{i j}=\frac{x_{i j}-z_{j}}{\max \left\{\max _{1 \leq i \leq m}\left\{x_{i j}\right\}-z_{j}, z_{j}-\min _{1 \leq i \leq m}\left\{x_{i j}\right\}\right\}} .
$$

If the target value is a cost indicator, the normalization expression is as follows:

$$
v_{i j}=\frac{z_{j}-x_{i j}}{\max \left\{\max _{1 \leq i \leq m}\left\{x_{i j}\right\}-z_{j}, z_{j}-\min _{1 \leq i \leq m}\left\{x_{i j}\right\}\right\}} .
$$

Step 4: definition of the target center vector

Based on the above transformation, the decision matrix is $\mathbf{V}=\left(v_{i j}\right)_{m \times n}$. The target center is

$$
v_{j}^{0}=\min \left\{v_{i j} \mid 1 \leq i \leq m\right\}, \quad j=1,2, \ldots, n .
$$

The target center vector is

$$
v^{0}=\left\{v_{1}^{0}, v_{2}^{0}, \ldots, v_{n}^{0}\right\} .
$$

Step 5: calculation of the bull's eye distance

According to the definition of grey target theory, $v^{0}$ is the target center of an $n$-dimensional ellipsoid grey target. The closer the target value of each solution is to the target center, the better the solution is. The bull's eye distance is expressed as 


$$
d_{i}=\left|v_{i}-v^{0}\right|=\sqrt{\sum_{j=1}^{n} \omega_{j}\left(v_{i j}-v_{j}^{0}\right)^{2}} .
$$

\section{Results and Discussion}

5.1. Case Study. In order to evaluate the performance of the proposed multiobjective economic operation optimization model for microgrid and the effectiveness of the improved hybrid algorithm, the wind/solar/diesel/battery stand-alone microgrid system on Yongxing island, in the South China Sea, is adopted as a case study. The optimal economic operation problem of this microgrid is solved by the SAPSO algorithm using MATLAB software.

The optimization model considers daily scheduling with a time interval of one hour. The forecast temperature, wind speed, and solar irradiance are shown in Figure 5. According to the mathematical model given in Section 2, using the forecast temperature, wind speed, and solar irradiance, the output power of PV system and wind turbine are calculated and presented in Figure 6. The hourly forecast load demand curve in one day is shown in Figure 7.

As can be seen from Figure 5, this island is rich in solar and wind energy resources, with high average wind speed and long sunshine time, which are $10.36 \mathrm{~m} / \mathrm{s}$ and 12 hours, respectively. However, the wind speed fluctuates greatly hour by hour. In addition, the island has a typical marine climate with a high average temperature of $27.4^{\circ} \mathrm{C}$. As shown in Figure 7, there are two peaks of load on this island, which are at 11 o'clock am and 19 o'clock pm, respectively.

The operation limits and operation and maintenance cost of the stand-alone microgrid system are shown in Table 1. The parameters of the pollutant emission coefficients and the penalty coefficients are presented in Tables 2 and 3 , respectively. Other simulation input data are shown in Table 4. The parameters for algorithms are presented in Table 5 .

5.2. Results Analysis. Based on the proposed SAPSO algorithm, the Pareto solution set of the multiobjective optimization problem is obtained, and the duplicate schemes are deleted. The eight feasible solutions are shown in Figure 8.

It can be seen from Figure 8 that the projection of the Pareto front on the $X Y$ plane is a straight line. It means that the economic cost and the environmental cost are not mutually exclusive. They both reach the maximum or minimum at the same time. The fuel cost of diesel generator accounts for the majority of the economic cost; the wind power and photovoltaic power generations do not produce polluting gas, while diesel generators release polluted exhaust gases. The more power generation from diesel generator, the higher economic cost and the higher corresponding environmental cost. Meanwhile, the economic cost and the environmental cost are both in general conflict with the battery depreciation cost. While the economic cost and the environmental cost decrease to the lowest, the battery depreciation cost increases to the highest. The following eight schemes are given for further study.

The economic cost, the battery depreciation cost, and the environmental cost of the above eight schemes are given in Table 6 . When the battery depreciation cost is the highest, $277.13 \$$, the economic cost and the environmental cost are the lowest, $2143.97 \$$ and $1191.09 \$$, respectively; when the battery depreciation cost is lowest, $208.46 \$$, the economic cost and the environmental cost are the highest, 2430.73\$ and $1350.41 \$$, respectively. The real total cost increases gradually from scheme one to scheme eight.

In order to evaluate the performance of each scheme and choose the optimal one from the above eight schemes, three decision-making methods are applied in this paper. The first two traditional methods use the subjective and objective linear weighted sum method to calculate the evaluation index values, respectively. Method three is based on the grey target decision-making theory. Then the results obtained from these three methods are compared. Since the orders of magnitude are different, the linear normalization is performed at first.

5.2.1. Method 1. Assume that each objective is equally important to the whole objective; thus the same weighting factor is given to the three objectives; that is, each one accounts for $1 / 3$, respectively. As shown in Table 7 , the calculation results show that the evaluation index value reduces at first and then gradually increases. Although the total cost of scheme one is the lowest, $3612.19 \$$, the evaluation index value is the largest, 0.9213 . The total cost of scheme $1,3612.19 \$$, is much less than that of scheme 8 , $3989.6 \$$, while the index value of scheme $1,0.9213$, is larger than that of scheme $8,0.9174$. The final results show that the fourth scheme has the lowest evaluation index value, 0.9016 , which means scheme four is the best one.

5.2.2. Method 2. Based on the simulation data obtained by the hybrid SAPSO algorithm, both the information entropy value and weighting factor of each objective are obtained by using the entropy weight method. As shown in Table 8, the weighting coefficient of the battery depreciation cost, $72.02 \%$, is much larger than the other two objectives, $14.05 \%$ and $13.94 \%$, respectively. From the information entropy theory, the smaller the entropy value of an index is, the greater the degree of its variation is and the more information it can provide. Thus it plays a more important role in a comprehensive evaluation and should be given a greater weighting factor, and vice versa. The battery depreciation cost reduces from $277.13 \$$ to $208.46 \$$, a decrease of about $33 \%$, while the other two indices increase by about $13 \%$. So a greater weighting factor is given to the battery depreciation cost. The calculation results are presented in Table 9. The results indicate that scheme 3 is the optimum, whose evaluation index value is 0.9051 . It can also be seen from Table 9 that the evaluation index value reduces at first and then gradually increases. The real total cost and the evaluation index value of scheme 8 are the largest at the same time, which are $3989.6 \$$ and 0.9367 , respectively. 


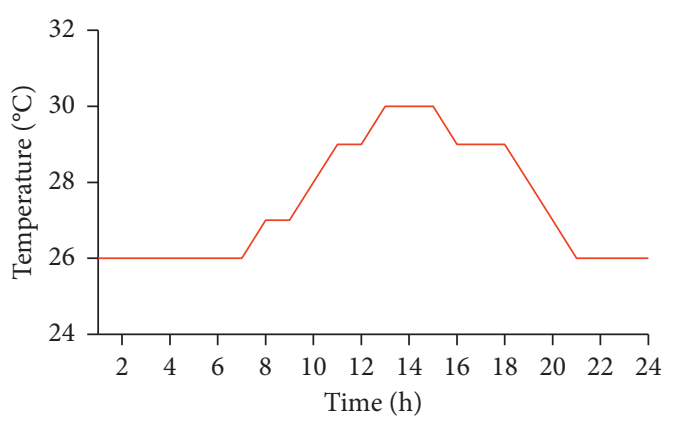

(a)

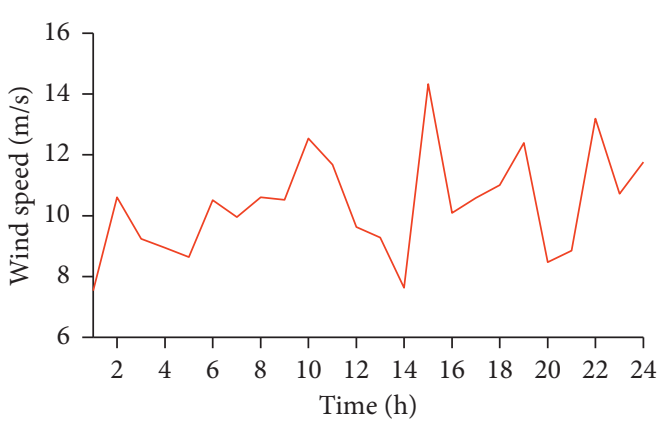

(b)

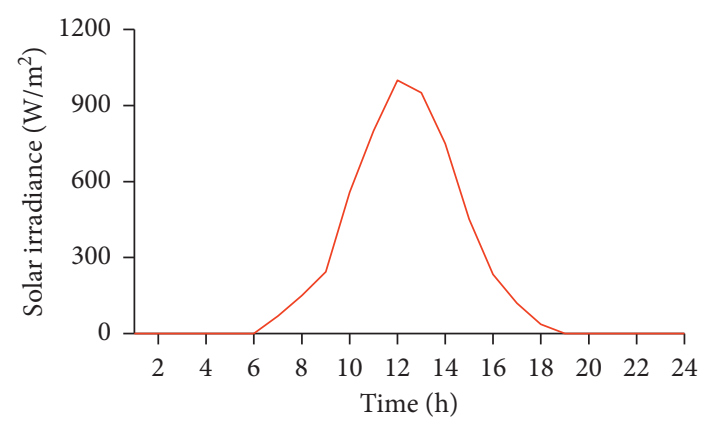

(c)

Figure 5: The hourly forecast temperature and renewable resources. (a) The temperature profile; (b) the solar irradiance profile; (c) the wind speed profile.

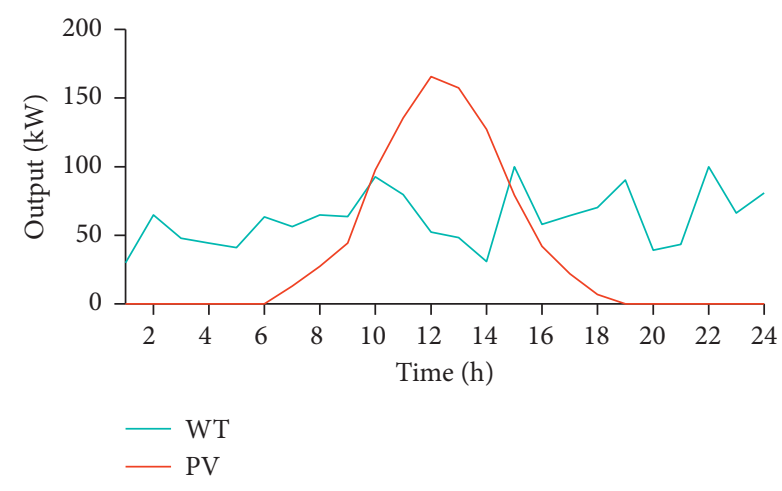

FIGURE 6: Output power of PV system and wind turbines.

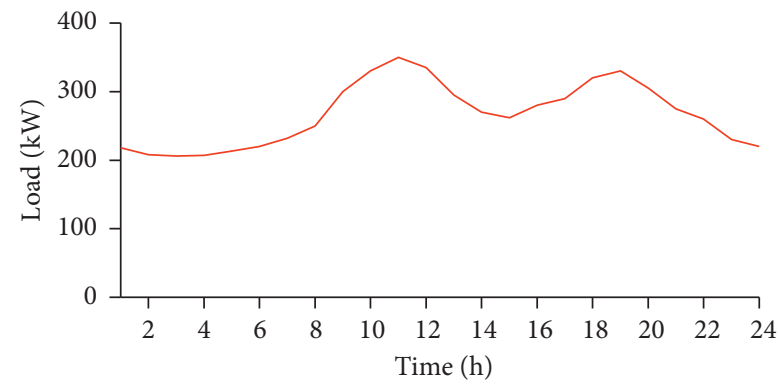

FIGURE 7: The hourly forecast load demand curve.

5.2.3. Method 3. Using the grey target decision-making theory based on entropy weight method mentioned in Section 4.2 , the target center vector $(-1,-1,-1)$ is calculated
TABLE 1: Operating parameters of the microgrid system.

\begin{tabular}{lccc}
\hline Type & $P_{\min }(\mathrm{kW})$ & $P_{\max }(\mathrm{kW})$ & $K_{\mathrm{OM}}(\$ / \mathrm{kWh})$ \\
\hline PV & 0 & 200 & 0.0096 \\
WT & 0 & 100 & 0.0296 \\
DE & 120 & 320 & 0.0524 \\
BS & -400 & 400 & 0.0648 \\
\hline
\end{tabular}

Table 2: Pollutant emission coefficients of different generation units.

\begin{tabular}{lcccc}
\hline \multirow{2}{*}{ Type } & \multicolumn{4}{c}{ Pollutant emission $\left(\mathrm{g} \cdot \mathrm{kW}^{-1} \cdot \mathrm{h}^{-1}\right)$} \\
& PV & WT & DE & BS \\
\hline $\mathrm{CO}_{2}$ & 0 & 0 & 232.037 & 0 \\
$\mathrm{SO}_{2}$ & 0 & 0 & 0.464 & 0 \\
$\mathrm{NO}_{\mathrm{x}}$ & 0 & 0 & 4.331 & 0 \\
$\mathrm{CO}$ & 0 & 0 & 2.320 & 0 \\
\hline
\end{tabular}

TABLE 3: Environmental value and penalty rate of different pollutants.

\begin{tabular}{lcc}
\hline Type & Environmental value $\left(\$ \cdot \mathrm{kg}^{-1}\right)$ & Penalty rate $\left(\$ \cdot \mathrm{kg}^{-1}\right)$ \\
\hline $\mathrm{CO}_{2}$ & 0.002875 & 0.210 \\
$\mathrm{SO}_{2}$ & 0.75 & 14.842 \\
$\mathrm{NO}_{\mathrm{x}}$ & 1.00 & 62.964 \\
$\mathrm{CO}$ & 0.125 & 0.125 \\
\hline
\end{tabular}

at first. Then the bull's eye distance of each scheme is obtained. As shown in Table 10, the bull's eye distance of the eight schemes decreases from 0.9420 to 0.9151 and then increases to 1.5122 . Scheme 2 has the smallest bull's eye 
TABle 4: Simulation input data.

\begin{tabular}{|c|c|}
\hline Parameter & Value \\
\hline \multicolumn{2}{|l|}{ PV } \\
\hline Nominal capacity of PV array $\left(P_{\text {rate_PV }}\right)$ & $200 \mathrm{~kW}$ \\
\hline Deteriorating factor $\left(\eta_{\mathrm{PV}}\right)$ & $98 \%$ \\
\hline Temperature factor $\left(\alpha_{\mathrm{TP}}\right)$ & $\% /{ }^{\circ} \mathrm{C}$ \\
\hline $\begin{array}{l}\text { Ambient temperature under standard test } \\
\text { condition }\left(T_{\mathrm{STC}}\right)\end{array}$ & $25^{\circ} \mathrm{C}$ \\
\hline Efficiency at standard test condition $\left(\eta_{\mathrm{STC}}\right)$ & $\%$ \\
\hline Nominal operating temperature of PV cell $\left(T_{\mathrm{NOCT}}\right)$ & $25^{\circ} \mathrm{C}$ \\
\hline \multicolumn{2}{|l|}{ Wind turbine } \\
\hline Nominal capacity of wind turbine $\left(P_{\text {rate_WT }}\right)$ & $100 \mathrm{~kW}$ \\
\hline Rated wind speed of wind turbine $\left(v_{r}\right)$ & $13 \mathrm{~m} / \mathrm{s}$ \\
\hline Cut-in wind speed $\left(v_{\text {cut_in }}\right)$ & $3 \mathrm{~m} / \mathrm{s}$ \\
\hline Cut-out wind speed $\left(v_{\text {cut_out }}\right)$ & $25 \mathrm{~m} / \mathrm{s}$ \\
\hline \multicolumn{2}{|l|}{ Diesel generator } \\
\hline Nominal power of diesel generator $\left(P_{\text {rate_gen }}\right)$ & $400 \mathrm{~kW}$ \\
\hline $\begin{array}{l}\text { Intercept coefficient of the fuel consumption curve } \\
\left(F_{0}\right)\end{array}$ & 0.084 \\
\hline Slope of the fuel consumption curve $\left(F_{1}\right)$ & 0.24 \\
\hline Unit price of diesel $\left(C_{\text {fuel }}\right)$ & $1.2 \$ / \mathrm{L}$ \\
\hline \multicolumn{2}{|l|}{ Battery system } \\
\hline Nominal capacity of the battery system $\left(E_{\text {bat }}\right)$ & $1000 \mathrm{kWh}$ \\
\hline Time interval $(\Delta t)$ & 1 hour \\
\hline Self-discharging factor $(\delta)$ & 0.01 \\
\hline Minimum state of charge $\left(\mathrm{SOC}_{\min }\right)$ & 0.4 \\
\hline Maximum state of charge $\left(\mathrm{SOC}_{\max }\right)$ & 0.9 \\
\hline Initial state of charge $\left(\mathrm{SOC}_{\text {in }}\right)$ & 0.7 \\
\hline Battery charging efficiency $\left(\eta_{\text {bat }, c h}\right)$ & 0.9 \\
\hline Battery discharging efficiency $\left(\eta_{\text {bat,dis }}\right)$ & 0.9 \\
\hline Battery replacement cost $\left(C_{\text {bat,rep }}\right)$ & $\begin{array}{l}488 \$ / \\
\mathrm{kWh}\end{array}$ \\
\hline
\end{tabular}

TABle 5: Parameters for algorithms.

\begin{tabular}{lc}
\hline Algorithm & Value \\
\hline SAPSO & \\
Population size $(N)$ & 600 \\
Maximum iteration number $(M)$ & 100 \\
Learning factor $\left(c_{1}\right)$ & 2.05 \\
Learning factor $\left(c_{2}\right)$ & 2.05 \\
Initial temperature $\left(T_{0}\right)$ & 100 \\
Annealing temperature factor $(k)$ & 0.5 \\
\hline IWPSO & \\
Population size $(N)$ & 600 \\
Maximum iteration number $(M)$ & 100 \\
Learning factor $\left(c_{1}\right)$ & 2.05 \\
Learning factor $\left(c_{2}\right)$ & 2.05 \\
\hline
\end{tabular}

distance, which means the corresponding solution is closest to the target center. So it is a satisfactory solution for this decision. The total cost of scheme $8,3989.6 \$$, is much larger than scheme 2, 3629.08\$; the bull's eye distance of scheme 8 , 1.5122 , is also much larger than that of scheme $2,0.9151$. It is also shown that the real total cost and the value of the evaluation index are consistent, which is closer to the actual situation.

For method one, the total cost of scheme 4 is relatively high and it is too subjective by artificially assigning weighting factors. What is more, it cannot reflect preferences

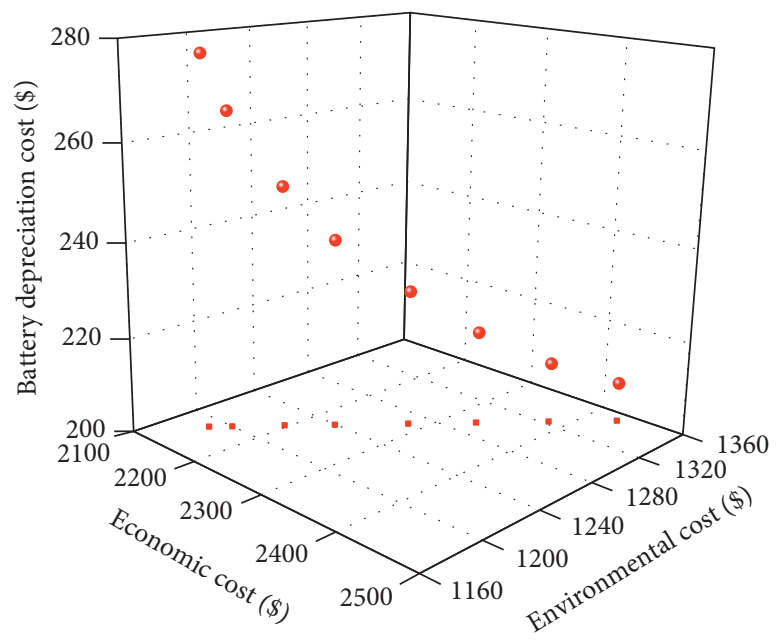

FIGURE 8: Pareto front solutions by the SAPSO algorithm.

TABle 6: Costs of different schemes.

\begin{tabular}{lccc}
\hline Scheme & $f_{c}(\$)$ & $f_{b}(\$)$ & $f_{e}(\$)$ \\
\hline 1 & 2143.97 & 277.13 & 1191.09 \\
2 & 2163.76 & 263.45 & 1201.87 \\
3 & 2196.34 & 251.67 & 1221.32 \\
4 & 2230.71 & 240.89 & 1239.29 \\
5 & 2282.14 & 229.23 & 1267.86 \\
6 & 2330.07 & 218.21 & 1294.49 \\
7 & 2381.79 & 213.65 & 1323.21 \\
8 & 2430.73 & 208.46 & 1350.41 \\
\hline
\end{tabular}

TABLe 7: The calculation results of method 1.

\begin{tabular}{lc}
\hline Scheme & Value \\
\hline 1 & 0.9213 \\
2 & 0.9134 \\
3 & 0.9054 \\
4 & 0.9016 \\
5 & 0.9017 \\
6 & 0.9047 \\
7 & 0.9102 \\
8 & 0.9174 \\
\hline
\end{tabular}

TABLE 8: Information entropy and weighting factors of different objectives.

\begin{tabular}{lccc}
\hline Objective & $f_{c}$ & $f_{b}$ & $f_{e}$ \\
\hline Information entropy & 0.9996 & 0.9977 & 0.9996 \\
Weighting factors (\%) & 14.05 & 72.02 & 13.94 \\
\hline
\end{tabular}

by giving the same weighting factor. For method two, due to the fact that the battery depreciation cost is one order of magnitude lower than the economic cost and the environmental protection cost, the entropy weight method lacks a horizontal comparison between the indicators in the process of weighting. However, method two is more objective than method one in dealing with the multiobjective decision-making problem. For method three, although the economic cost and the environmental cost of scheme 2 are 
TABLE 9: The calculation results of method 2.

\begin{tabular}{lc}
\hline Scheme & Value \\
\hline 1 & 0.9122 \\
2 & 0.9077 \\
3 & 0.9051 \\
4 & 0.9053 \\
5 & 0.9104 \\
6 & 0.9172 \\
7 & 0.9265 \\
8 & 0.9367 \\
\hline
\end{tabular}

TABle 10: Bull's eye distance of different schemes.

\begin{tabular}{lc}
\hline Scheme & Value \\
\hline 1 & 0.9420 \\
2 & 0.9151 \\
3 & 0.9487 \\
4 & 1.0332 \\
5 & 1.1607 \\
6 & 1.2831 \\
7 & 1.4067 \\
8 & 1.5122 \\
\hline
\end{tabular}

not the lowest, both are relatively low. At the same time, this reflects the objectivity and the trade-off between subobjectives of a multiobjective optimization problem.

The output results of different generation units at the minimum economic and environmental cost, the minimum battery depreciation cost, and the optimal scheme are shown in Figures 9-11, respectively. During 10:00-16:00, the solar resource is rich, the total available generation is greater than load demand, and the battery bank is charged. While the renewable energy resource is poor from 18:00 to 21:00, the battery bank is discharged. In general, because the unit generation cost of diesel generator is higher than that of the battery system, it will increase the output power and the generation cost of diesel generator to decrease the life loss cost of battery system. Because of the abundant renewable resources and the role of battery system, the load rate of diesel generator is relatively low. But it is always located in the economic operating ranges of diesel generator (30 80\%). Table 11 lists the daily power generation of diesel generator, the charging capacity of storage battery when solar energy is rich, and the discharging capacity of storage battery at the peak of load demand at night, respectively.

Figure 9 shows that the battery starts charging from 10 o'clock in the morning until 15 o'clock in the afternoon, absorbing about $264.16 \mathrm{kWh}$ of renewable energy within five hours. Meanwhile, for the load peak during 18:00-20:00 pm, the energy storage system discharges $270.54 \mathrm{kWh}$ of electrical energy. Among the whole optimization cycle, although the economic cost is the lowest, 2,143.97\$, the battery charging and discharging capacity is $901.16 \mathrm{kWh}$, which is the highest, and the corresponding battery depreciation cost is also the largest.

In Figure 10, it can be seen that the battery bank is charged between 12:00 and 15:00, and the total 192.04 kWh electricity power is absorbed. The charging process lasts only

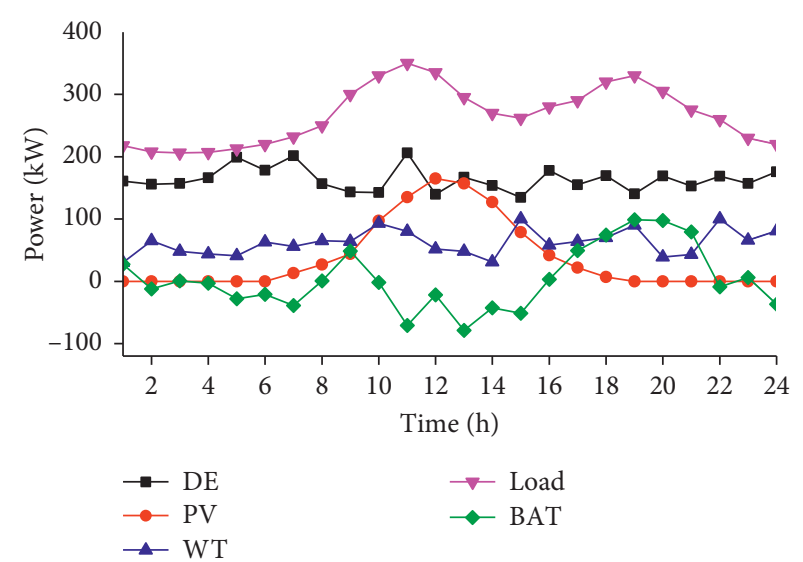

Figure 9: Output power of generation units at the minimum economic and environmental cost.

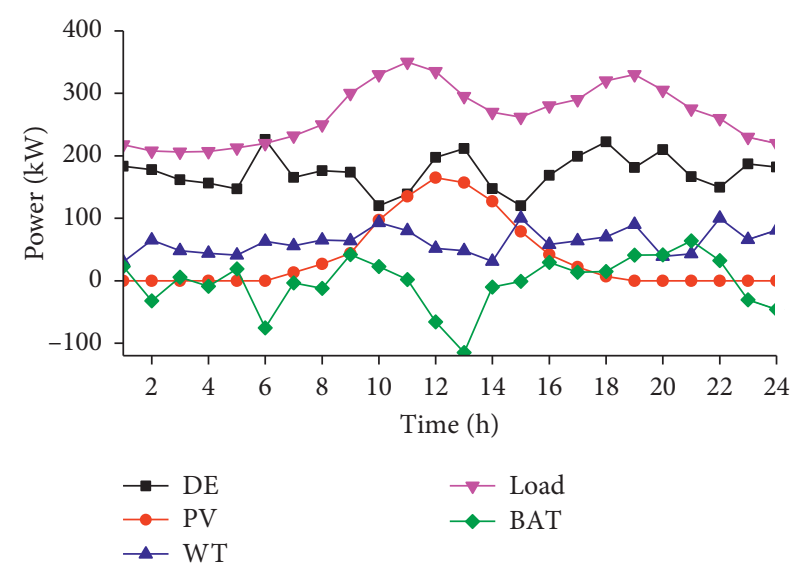

FIgURE 10: Output power of generation units at the minimum battery depreciation cost.

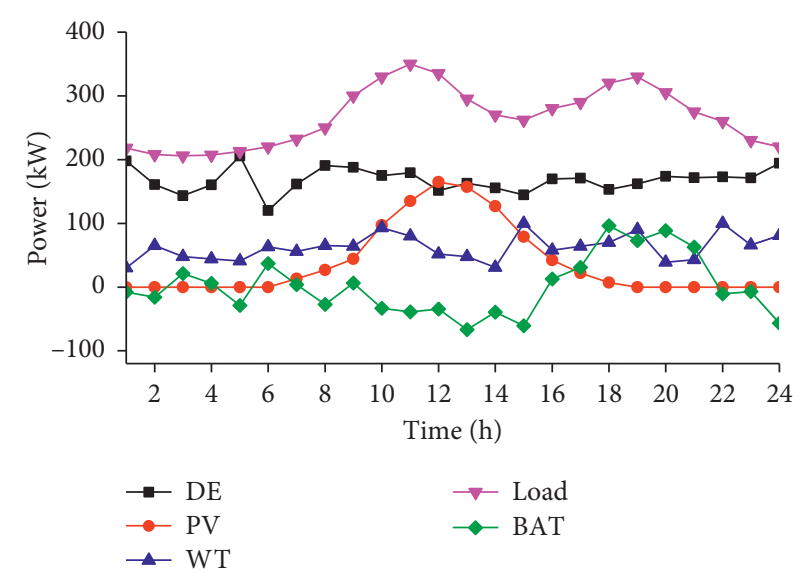

Figure 11: Output power of generation units for scheme 2.

three hours. During the load peak, from 18 to 20 o'clock in the evening, only $96.93 \mathrm{kWh}$ of electricity is released, because the charging and discharging cost of energy storage system is much lower than generation cost of diesel generator. Although the battery cost is reduced, only 208.46\$, 
TABLE 11: The daily power generation of diesel generator and charging and discharging capacity of battery system.

\begin{tabular}{lcccc}
\hline Scheme & $\begin{array}{c}\text { Diesel generator } \\
(\mathrm{kWh})\end{array}$ & $\begin{array}{c}\text { Total charging and } \\
\text { discharging capacity }\end{array}$ & $\begin{array}{c}\text { Battery system (kWh) } \\
\text { Charging capacity (when } \\
\text { solar energy is rich) }\end{array}$ & $\begin{array}{c}\text { Discharging capacity (when } \\
\text { load peak is at night) }\end{array}$ \\
\hline $\begin{array}{l}\text { The minimum of economic } \\
\text { cost }\end{array}$ & 3927.67 & 901.16 & 264.16 & 270.54 \\
$\begin{array}{l}\text { The minimum of battery } \\
\text { depreciation cost }\end{array}$ & 4168.54 & 750.71 & 192.04 & 96.93 \\
The optimal scheme & 4034.99 & 865.48 & 294.88 & 257.61 \\
\hline
\end{tabular}

the cost of diesel generator is increased, which is $2,430.73 \$$. The total cycle charging and discharging electricity of battery system is the lowest in one day among all the schemes, which is just $750.71 \mathrm{kWh}$. That means the energy storage system is not utilized reasonably in this scheme.

Figure 11 shows the output power of generation units for the optimal scheme. At eight o'clock in the morning, the battery system starts to charge until 15 o'clock in the afternoon. The charging process lasts even more than six hours. The total electrical energy absorbed by battery system from renewable energy generation is $294.88 \mathrm{kWh}$. At the load peak between 18:00 and 20:00 in the evening, the energy storage system discharges $257.61 \mathrm{kWh}$ of electrical energy. From 22 to 2 o'clock in early morning, the load is at a low level, and the output power of diesel generator is smoothed by charging the battery system. The output power of the diesel generator is relatively stable and only fluctuates in a very small range. Avoiding drastic fluctuations in power is beneficial to reducing mechanical damage and prolonging lifespan of the diesel generator. The energy storage battery system plays the role of "shaving the peak and filling the valley" in this microgrid system. It is consistent with the expected operation effect.

Figure 12 shows the hourly SOC of energy storage battery system in one day. The battery system is charged for about 6 hours until 15:00 pm and the SOC reaches a maximum of 0.83 . After the discharging during the load peak at night, the SOC reaches daily lowest value, which is about 0.46 at $21: 00 \mathrm{pm}$. The values of SOC satisfy the SOC constraints.

The microgrid cost distribution of the optimal scheme is shown in Figure 13. It can be seen that the two largest proportions of the whole operating cost are fuel cost and environmental cost, which are $53.49 \%$ and $33.67 \%$, respectively. The fuel cost accounts for more than one half of the whole operating expenses. Once the fuel price or transportation distance increases, the fuel cost will rise, which will lead to a further increase in the proportion of fuel costs to power generation costs. Therefore, reducing the fuel consumption is critical to improve the economics for remote island microgrid. The battery depreciation cost only accounts for $5.72 \%$ of the entire operating cost; that is because only the replacement cost of the battery system is considered, while the construction, labour, and transportation costs of replacing the battery system are not included in this paper.

To make a comparison of the performance difference between the simulated annealing particle swarm optimization

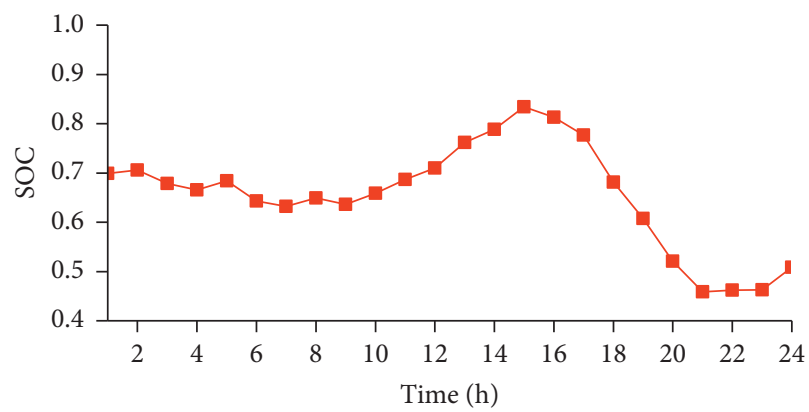

FIGURE 12: SOC of storage battery for scheme 2.

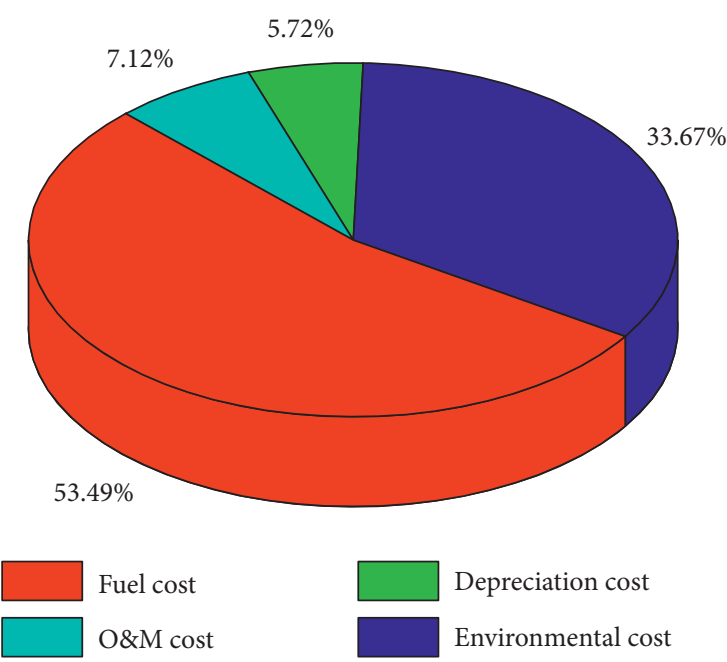

Figure 13: Microgrid cost distribution of the optimal scheme.

(SAPSO) algorithm and the inertia weight particle swarm optimization (IWPSO) algorithm, it is assumed that each objective is equally important and given the same weighting factor to obtain the total expenses. Each algorithm performs 10 iterations and then compares the average of the fitness values. Convergence curves of both algorithms are shown in Figure 14. It can be seen that the SAPSO algorithm has stronger search ability than the IWPSO algorithm in the early stage. In the whole search process, the IWPSO algorithm is prone to fall into local optimum and produce premature convergence; the final fitness value is about $3980 \$$. However, the SAPSO algorithm can quickly jump out after a short time of iterative operation so as to avoid falling into the local optimal solution; the final fitness value is about $3760 \$$, which 


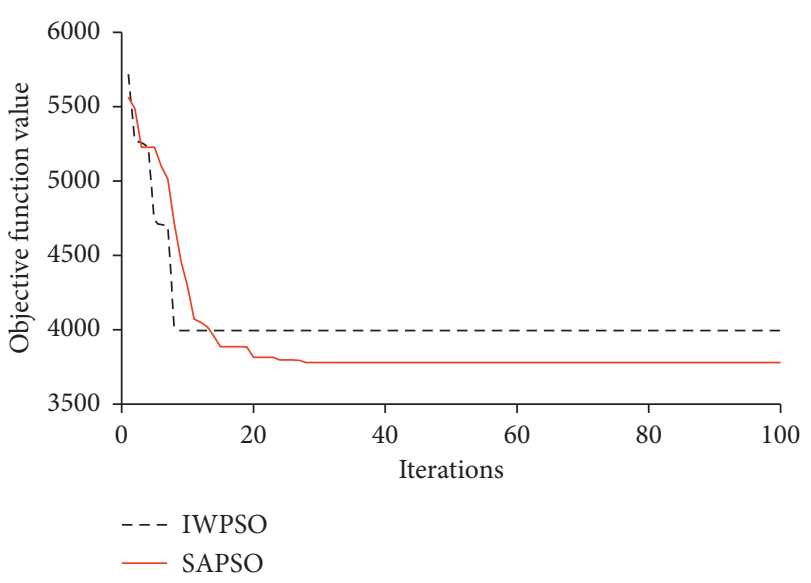

FIgURe 14: Convergence curve for the basic PSO and the SAPSO.

is $5.53 \%$ less than that of the IWPSO algorithm. The SAPSO algorithm tends to be stable after 25 iterations, while IWPSO algorithm tends to be stable after 9 iterations. Although the IWPSO algorithm has a faster convergence, the proposed SAPSO algorithm can search for a smaller global optimal objective function fitness value and the convergence process is more robust.

\section{Conclusion}

In this study, a novel economic operation optimization model and optimization method are proposed for a standalone microgrid system, which includes photovoltaic panels, wind turbines, diesel generators, and energy storage battery system. In the operation optimization model, the output power of the storage battery system and diesel generator are taken as the optimization decision variables. For this purpose, a multiobjective function is defined on minimizing the costs of generation, battery depreciation, and environmental protection. An improved hybrid SAPSO algorithm is proposed for optimal search for the two decision variables while satisfying the load demand. The results are compared with the results obtained by IWPSO algorithm. Then the grey target decision-making theory based on entropy weight method is adopted to make the decision of the best trade-off scheme. The results are compared with the results obtained by two other traditional decision-making methods.

The results show that the economic cost and the environmental cost are not mutually exclusive for the standalone microgrid on a remote island. The battery depreciation cost is conflicting with both the economic cost and the environmental cost. With the increased battery depreciation cost, the economic cost and the environmental cost both decrease. The simulation results demonstrate that the energy storage battery system can absorb the renewable energy when the renewable energy is rich at daytime, while releasing energy during the peak load at night, which plays the role of "shaving the peak and filling the valley," as well as smoothing the output power of traditional diesel generator. The total charging and discharging capacity of the battery system reaches the maximum when the economic cost is at the minimum, while the battery system is not used reasonably when the battery depreciation cost is at the minimum. The fuel cost in stand-alone microgrid is a key factor for the whole operating expenses. It is confirmed that the improved hybrid SAPSO algorithm can find a better objective function value and it exhibits better robustness than the traditional PSO algorithm. It is also shown that the proposed grey target decision-making theory based on entropy weight method can find optimal compromise solution. The optimal scheme obtained by the grey target decision method is consistent with the expected operation effect. The proposed operation optimization method and decision-making theory provide a useful tool for the stand-alone microgrid optimal operation.

\section{Data Availability}

The data used to support the findings of this study are available from the corresponding author upon request.

\section{Conflicts of Interest}

The authors declare no conflicts of interest.

\section{Acknowledgments}

This work was financially supported by "National Key R\&D Program of China (supported by Ministry of Science and Technology of China, no. 2016YFC0305001)" and "the National Science and Technology Support Program" (supported by Ministry of Science and Technology of China, no. 2014BAC01B05).

\section{References}

[1] F. Feijoo and T. K. Das, "Emissions control via carbon policies and microgrid generation: a bilevel model and Pareto analysis," Energy, vol. 90, pp. 1545-1555, 2015.

[2] S. M. Mortazavi, A. Maleki, and H. Yousefi, "Analysis of robustness of the Chinese economy and energy supply/demand fluctuations," International Journal of Low-Carbon Technologies, vol. 14, no. 2, pp. 147-159, 2019.

[3] N. Duic, G. Krajacic, and M. Dagracacarvalho, "RenewIslands methodology for sustainable energy and resource planning for islands," Renewable and Sustainable Energy Reviews, vol. 12, no. 4, pp. 1032-1062, 2008.

[4] A. S. Bahaj, "Generating electricity from the oceans," Renewable and Sustainable Energy Reviews, vol. 15, no. 7, pp. 3399-3416, 2011.

[5] A. Maleki and F. Pourfayaz, "Optimal sizing of autonomous hybrid photovoltaic/wind/battery power system with LPSP techonology by using evolutionary algorithms," Solar Energy, vol. 115, no. 1, pp. 471-483, 2015.

[6] P. Pal, V. Mukherjee, and A. Maleki, "Economic and performance investigation of hybrid PV/wind/battery energy system for isolated Andaman and Nicobar islands, India," International Journal of Ambient Energy, pp. 1-19, 2018.

[7] P. Nagapurkar and J. D. Smith, "Techno-economic optimization and environmental life cycle assessment (LCA) of microgrids located in the US using genetic algorithm," Energy Conversion and Management, vol. 181, pp. 272-291, 2019.

[8] S. G. Sigarchian, M. S. Orosz, H. F. Hemond, and A. Malmquist, "Optimum design of a hybrid PV-CSP-LPG 
microgrid with particle swarm optimization technique," Applied Thermal Engineering, vol. 109, pp. 1031-1036, 2016.

[9] J. Jung and M. Villaran, "Optimal planning and design of hybrid renewable energy systems for microgrids," Renewable and Sustainable Energy Reviews, vol. 75, pp. 180-191, 2017.

[10] A. Maleki, "Modeling and optimum design of an off-grid PV/ WT/FC/diesel hybrid system considering different fuel prices," International Journal of Low-Carbon Technologies, vol. 13, no. 2, pp. 140-147, 2018.

[11] A. L. Bukar, C. W. Tan, and K. Y. Lau, "Optimal sizing of an autonomous photovoltaic/wind/battery/diesel generator microgrid using grasshopper optimization algorithm," Solar Energy, vol. 188, pp. 685-696, 2019.

[12] L. M. Halabi, S. Mekhilef, L. Olatomiwa, and J. Hazelton, "Performance analysis of hybrid PV/diesel/battery system using HOMER: a case study Sabah, Malaysia," Energy Conversion and Management, vol. 144, no. 15, pp. 322-339, 2017.

[13] J. Manwell, A. Rogers, G. Hayman et al., Hybrid2: A Hybrid System Simulation Model Theory Manual, Renewable Energy Research Laboratory, Department of Mechanical Engineering, University of Massachusetts, Boston, MA, USA, 2006.

[14] B. Yan, B. Wang, L. Zhu et al., "A novel, stable, and economic power sharing scheme for an autonomous microgrid in the energy internet," Energies, vol. 8, no. 11, pp. 12741-12764, 2015.

[15] G.-C. Liao, "Solve environmental economic dispatch of smart microgrid containing distributed generation system: using chaotic quantum genetic algorithm," International Journal of Electrical Power \& Energy Systems, vol. 43, no. 1, pp. 779-787, 2012.

[16] F. A. Mohamed and H. N. Koivo, "System modelling and online optimal management of microgrid using mesh adaptive direct search," International Journal of Electrical Power \& Energy Systems, vol. 32, no. 5, pp. 398-407, 2010.

[17] Y. Yi, L. Xia, Y. Tao et al., "Microgrid energy optimal dispatch considering the security and reliability," Proceeding of the CSEE, vol. 34, no. 19, pp. 3080-3088, 2014.

[18] L. Guo, N. Wang, H. Lu, X. Li, and C. Wang, "Multi-objective optimal planning of the stand-alone microgrid system based on different benefit subjects," Energy, vol. 116, pp. 353-363, 2016.

[19] M. Azaza and F. Wallin, "Multi objective particle swarm optimization of hybrid micro-grid system: a case study in Sweden,” Energy, vol. 123, pp. 108-118, 2017.

[20] W. Zhang, A. Maleki, and M. A. Rosen, "A heuristic-based approach for optimizing a small independent solar and wind hybrid power scheme incorporating load forecasting," Journal of Cleaner Production, vol. 241, Article ID 117920, 2019.

[21] G. Carpinelli, F. Mottola, D. Proto, and A. Russo, "A multiobjective approach for microgrid scheduling," IEEE Transactions on Smart Grid, vol. 8, no. 5, pp. 2109-2118, 2017.

[22] T. Aziz, N.-A. Masood, S. R. Deeba, W. Tushar, and C. Yuen, "A methodology to prevent cascading contingencies using BESS in a renewable integrated microgrid," International Journal of Electrical Power \& Energy Systems, vol. 110, pp. 737-746, 2019.

[23] Y. Zheng, B. M. Jenkins, K. Kornbluth, A. Kendall, and C. Træholt, "Optimization of a biomass-integrated renewable energy microgrid with demand side management under uncertainty," Applied Energy, vol. 230, pp. 836-844, 2018.

[24] A. S. Jacob, R. Banerjee, and P. C. Ghosh, "Sizing of hybrid energy storage system for a PV based microgrid through design space approach," Applied Energy, vol. 212, pp. 640-653, 2018.
[25] L. Wang, Q. Li, R. Ding, M. Sun, and G. Wang, "Integrated scheduling of energy supply and demand in microgrids under uncertainty: a robust multi-objective optimization approach," Energy, vol. 130, pp. 1-14, 2017.

[26] A. Mleki, "Design and optimization of autonomous solarwind-reverse osmosis desalination systems coupling battery and hydrogen energy storage by an improved bee algorithm," Desalination, vol. 435, pp. 221-234, 2018.

[27] M. B. Shadmand and R. S. Balog, "Multi-objective optimization and design of photovoltaic-wind hybrid system for community smart DC microgrid," IEEE Transaction on Smart Grid, vol. 5, no. 5, pp. 2635-2643, 2014.

[28] A. Maleki, "Optimal operation of a grid-connected fuel cell based combined heat and power systems using particle swarm optimisation for residential sector," International Journal of Ambient Energy, vol. 47, pp. 1-8, 2019.

[29] T. Kerdphol, K. Fuji, Y. Mitani, M. Watanabe, and Y. Qudaih, "Optimization of a battery energy storage system using particle swarm optimization for stand-alone microgrids," International Journal of Electrical Power \& Energy Systems, vol. 81, pp. 32-39, 2016.

[30] G. Li, X. Zhai, Y. Li, B. Feng, Z. Wang, and M. Zhang, "Multiobjective optimization operation considering environment benefits and economy based on ant colony optimization for isolated micro-grids," Energy Procedia, vol. 104, pp. 21-26, 2016.

[31] A. Cagnano, A. Caldarulo Bugliari, and E. De Tuglie, “A cooperative control for the reserve management of isolated microgrids," Applied Energy, vol. 218, pp. 256-265, 2018.

[32] H. Wu, X. Liu, and M. Ding, "Dynamic economic dispatch of a microgrid: mathematical models and solution algorithm," International Journal of Electrical Power \& Energy Systems, vol. 63, pp. 336-346, 2014.

[33] H. Karimi and S. Jadid, "Optimal microgrid operation scheduling by a novel hybrid multiobjective and multi-attribute decision-making framework," Energy, vol. 186, Article ID 115912, 2019.

[34] M. H. Moradi, M. Abedini, and S. M. Hosseinian, "Optimal operation of autonomous microgrid using HS-GA," International Journal of Electrical Power \& Energy Systems, vol. 77, pp. 210-220, 2016.

[35] W. Zhang, A. Maleki, M. A. Rosen, and J. Liu, "Sizing a standalone solar-wind-hydrogen energy system using weather forecasting and a hybrid search optimization algorithm," Energy Conversion and Management, vol. 180, pp. 609-621, 2019.

[36] J. Lu, W. Wang, Y. Zhang, and S. Cheng, "Multi-objective optimal design of stand-alone hybrid energy system using entropy weight method based on HOMER," Energies, vol. 10, no. 10, p. 1664, 2017.

[37] G. Li, W. Liu, B. Jiao, and C. Wang, "Multi-objective optimal planning design method for stand-alone microgrid system," Proceedings of the CSEE, vol. 34, no. 4, pp. 524-536, 2014.

[38] D. Thomas, O. Deblecker, and C. S. Ioakimidis, "Optimal design and techno-economic analysis of an autonomous small isolated microgrid aiming at high RES penetration," Energy, vol. 116, pp. 364-379, 2016.

[39] N. Nikmehr and S. N. Ravadanegh, "Heuristic probabilistic power flow algorithm for microgrids operation and planning," IET Generation, Transmission \& Distribution, vol. 9, no. 11, pp. 985-995, 2015.

[40] H. Tazvinga, B. Zhu, and X. Xia, "Energy dispatch theory for a photovoltaic-wind-diesel-battery hybrid power system," Solar Energy, vol. 108, pp. 412-420, 2014. 
[41] Y. Azoumah, D. Yamegueu, P. Ginies, Y. Coulibaly, and P. Girard, "Sustainable electricity generation for rural and peri-urban populations of sub-Saharan Africa: the "flexyenergy" concept," Energy Policy, vol. 39, no. 1, pp. 131-141, 2011.

[42] A. M. A. Haidar, P. N. John, and M. Shawal, "Optimal configuration assessment of renewable energy in Malaysia," Renewable Energy, vol. 36, no. 2, pp. 881-888, 2011.

[43] C. Liu, X. Wang, and X. Wu, "A multi-layer dispatch theory of combined wind-storage systems considering optimization of battery units," Power System Technology, vol. 40, no. 10, pp. 3029-3037, 2016.

[44] E. I. Vrettos and S. A. Papathanassiou, "Operating policy and optimal sizing of a high penetration RES-BESS system for small isolated grids," IEEE Transactions on Energy Conversion, vol. 26, no. 3, pp. 744-756, 2011.

[45] K. Qian, Y. Yuan, X. Shi et al., "Environmental benefits analysis of distributed generation," Proceedings of the CSEE, vol. 28, no. 29, pp. 11-15, 2008.

[46] G. Zhang, B. Wu, A. Maleki, and W. Zhang, "Simulated annealing-chaotic search algorithm based optimization of reverse osmosis hybrid desalination system driven by wind and solar energies," Solar Energy, vol. 173, pp. 964-975, 2018. 